\title{
Pengaruh daya tarik program insentif dan orientasi kapabilitas supervisor terhadap keinginan pindah kerja
}

\author{
Mirza Norma Fitalia Rahmi ${ }^{1}$, Zainal Ilmi ${ }^{2}$, Robiansyah ${ }^{3}$ \\ Fakultas Ekonomi dan Bisnis Univesitas Mulawarman, Samarinda. \\ ${ }^{1}$ Email: thiedoren@gmail.com \\ ${ }^{2}$ Email: zainal.ilmi@feb.unmul.ac.id \\ ${ }^{3}$ Email: robiansyah@feb.unmul.ac.id
}

\begin{abstract}
Abstrak
Penelitian ini bertujuan untuk mengetahui pengaruh daya tarik program insentif dan kemampuan atasan terhadap niat berpindah agen pada PT. AXA Financial Indonesia cabang Samarinda. Jenis penelitian yang digunakan dalam penelitian ini adalah penelitian explanatory dengan pendekatan kuantitatif. Analisis data menggunakan deskriptif, dan regresi. Hasil penelitian menunjukkan bahwa daya tarik program insentif dan orientasi kemampuan pengawas memiliki pengaruh signifikan yang negatif terhadap niat berpindah. Hasil analisis menunjukkan bahwa orientasi daya tarik dan orientasi kemampuan insentif akan memberikan pengaruh yang signifikan terhadap penurunan niat berpindah.
\end{abstract}

Kata Kunci: Daya tarik program insentif

\section{The effect of the appeal of the incentive program and the orientation of the supervisor's capabilities on the desire to move work}

\begin{abstract}
This research aims to verify the influence of incentive program attractiveness and supervisor capability orientation on agent turnover intention at PT. AXA Financial Indonesia cabang Samarinda. This type of research used in this research is an explanatory research with a quantitative approach. Data analysis using descriptive, and regression. The results showed that incentive program attractiveness and supervisor capability orientation have a negative significant effect on turnover intention. The results of the analysis showed that the incentive program attractiveness and supervisor capability orientation will provide a significant influence to decrease turnover intention.
\end{abstract}

Keywords: Incentive program attractiveness 


\section{PENDAHULUAN}

Salah satu faktor penentu keberhasilan perusahaan adalah faktor tenaga kerja atau manusia. Manusia adalah sumber daya yang sangat penting, terlebih lagi bagi perusahaan yang menawarkan jasa seperti perusahaan asuransi dimana sumber daya manusia memegang peran sebagai ujung tombak perusahaan. Dalam bisnis asuransi, agen merupakan salah satu aset yang dimiliki perusahaan. Kinerja agen sangat menentukan keberhasilan perusahaan karena agen merupakan pihak yang mencari dan berhubungan langsung dengan nasabah asuransi.

PT. AXA Financial Indonesia adalah salah satu perusahaan asuransi di Indonesia yang bergerak dibidang jasa keuangan berskala internasional. Perusahaan ini menawarkan serangkaian produk jasa keuangan untuk perusahaan atau individu dalam bentuk asuransi jiwa, asuransi kerugian, manajemen keuangan, reasuransi dan perlindungan kesehatan melalui para agennya.

Ketika menjalankan peran dan tanggung jawabnya, para agen dituntut untuk memenuhi target. Dengan terpenuhinya target maka agen dapat dikatakan memiliki kinerja yang bagus. Namun pada kenyataannya tidak semua agen dapat memenuhi target yang sudah ditetapkan oleh perusahaan. Ketidakberhasilaan ini akan berdampak pada ketidaknyamanan dalam bekerja yang dapat menimbulkan halhal yang berakibat buruk bagi perusahaan dan agen yang bersangkutan. Antara lain, timbulnya niat atau kecenderungan untuk keluar dari perusahaan.

Berdasarkan data yang diperoleh selama tahun 2016 total agen (financial consultant) yang dimiliki oleh AXA Financial Indonesia cabang Samarinda sebanyak 88 orang. Sepanjang tahun 2016 pula, AXA Financial Indonesia cabang Samarinda merekrut sebanyak 67 agen baru, dan sebanyak 69 agen keluar dari perusahaan. Hal ini menunjukkan bahwa tingginya turnover (keinginan pindah kerja) telah menjadi masalah yang serius bagi perusahaan. Turnover bagi agen merupakan salah satu jalan keluar untuk mendapatkan keadaan yang lebih baik, namun bagi perusahaan hal ini merupakan kerugian yang harus dihadapi. Beberapa alasan bagi agen yang berkeinginan untuk berpindah, umumnya dikarenakan faktor manajemen yang kurang baik, tekanan dari perusahaan, dan adanya ketidakpuasan akan kinerja agen itu sendiri.

Perusahaan asuransi yang memiliki manajemen yang baik, haruslah memperhatikan setiap aspek yang dibutuhkan oleh para agennya. Misalnya dengan memperhatikan dan menyesuaikan antara kebijakan perusahaan dengan kebutuhan dan harapan agennya. Pengelolaan sistem kompensasi dimana insentif diberikan kepada agen berdasarkan kinerja dari setiap agen akan berdampak pada loyalitas agen itu sendiri. Program insentif yang dikelola secara benar akan menumbuhkan loyalitas dan akan menurunkan tingkat keinginan berpindah.

Adapun usaha lain yang dapat dilakukan perusahaan asuransi dalam menekan angka keinginan berpindah adalah dengan melakukan pengawasan terhadap para agennya. Supervisor sangat berperan penting dalam hal ini, dimana supervisor dituntut kepiawaiannya dalam mengembangkan kemampuan dan keterampilan 
agen-agennya. Orientasi kapabilitas supervisor merupakan perilaku supervisor dalam melakukan pengawasan yang lebih menekankan perhatianya pada pengembangan keterampilan dan kemampuan individu tenaga penjual yang diawasi. Hal ini ditunjukkan untuk memastikan bahwa agen tersebut memiliki serangkaian ketrampilan dan kemampuan yang membawa kinerja yang baik untuk meningkatkan kemampuan tenaga penjualan, mengawasi kegiatan tenaga penjualan, memberikan umpan balik yang positif dan mendorong mereka agar fokus dalam mencapai target.

Penelitian ini didukung oleh penelitian sebelumnya yang dilakukan oleh Sara Gable, Rothrauff, Thornburg, dan Mauzy (2007) yang menyatakan bahwa program insentif dapat menekan tingkat turnover. Chun-Chang Lee, Hsiung Huang, Yi Zhao (2010) juga menyatakan bahwa tingkat gaji, kepuasan kerja serta komitmen organisasi yang tinggi akan menyebabkan turnover yang lebih rendah. Penelitian yang dilakukan oleh David Krackhardt, McKenna, Porter, dan Steers (1981) yang bertujuan untuk menentukan apakah turnover bisa dikendalikan melalui intervensi pengawasan. Dari penelitian tersebut menyatakan bahwa pengawasan memang bisa mengakibatkan rendahnya tingkat turnover. Penelitian Syarifah Nazenin (2014) menunjukkan bahwa turnover intention dipengaruhi oleh kepuasan kerja dengan indikator pekerjaan itu sendiri, gaji/upah, kesempatan promosi, pengawasan, dan rekan kerja.

\section{Daya Tarik Program Insentif}

Pada dasarnya, program insentif dijalankan dengan tujuan agar karyawan, khususnya disini tenaga penjual (agen) termotivasi untuk meningkatkan produktivitas, merangsang para agen asuransi untuk mampu berkerja melebihi standar yang telah ditentukan oleh perusahaan, dan bertahan di perusahaan. Daya tarik program insentif merupakan persepsi para agen terhadap seberapa menarik program insentif yang ditawarkan perusahaan dibandingkan dengan perusahaan lain.

Panggabean (2004:89) mengatakan bahwa insentif merupakan penghargaan dalam bentuk uang yang diberikan kepada mereka yang dapat bekerja melampaui standar yang telah ditentukan. Selanjutnya menurut Mangkunegara (2009:89) Insentif adalah suatu bentuk motivasi yang dinyatakan dalam bentuk uang atas dasar kinerja yang tinggi dan juga merupakan rasa pengakuan dari pihak organisasi terhadap kinerja karyawan dan kontribusi terhadap organisasi (perusahaan).

Berdasarkan pendapat para ahli diatas, dapat disimpulkan bahwa insentif adalah program yang direncanakan oleh perusahaan yang diberikan dalam bentuk uang kepada karyawan sebagai motivasi agar karyawan terus meningkatkan kinerjanya.

\section{Orientasi Kapabilitas Supervisor}

Orientasi kapabilitas supervisor adalah perilaku supervisor dalam melakukan pengawasan yang lebih menekankan perhatiannya pada pengembangan keterampilan dan kemampuan individu tenaga penjual yang diawasi. Hal ini ditunjukkan untuk 
memastikan bahwa tenaga penjual memiliki serangkaian ketrampilan dan kemampuan yang membawa kinerja yang baik. (Challagalla dan Shervani, 1996:98).

Dalam orientasi kapabilitas, supevisor memberi arahan kepada tenaga penjual untuk meningkatkan keahlian dan kemampuan mengharuskan supervisor untuk dapat memahami kemampuan-kemampuan dari tenaga penjualnya. Hal ini memungkinkan supervisor untuk mempelajari kekuatan dan kelamahan setiap tenaga penjualnya. Dengan demikian supervisor mampu memberikan kiat-kiat yang berguna, pengetahuan dan metode-metode yang bermanfaat bagi tenaga penjual itu sendiri. Interaksi ini memiliki kemungkinan untuk memotivasi tenaga penjual untuk meningkatkan kinerja sesuai kriteria yang ditetapkan supervisor dan juga untuk meningkatkan kepekaan tenaga penjual terhadap pendekatan dari supervisor, yang mengharapkan perbaikan kinerja dari tenaga penjual (Mursid, 2008:110).

\section{Keinginan Pindah Kerja (Turnover Intention)}

Secara garis besar, keinginan pindah kerja adalah aliran para pegawai yang masuk dan keluar perusahaan. Menurut Robbins dan Judge (2007:38) turnover adalah tindakan pengunduran diri secara permanen yang dilakukan oleh karyawan baik secara sukarela ataupun tidak secara sukarela. Turnover dapat berupa pengunduran diri, perpindahan keluar unit organisasi, pemberhentian atau kematian anggota organisasi. Sedangkan menurut Zeffane (1994:24-25) turnover intention adalah kecendrungan atau niat karyawan untuk berhenti berkerja dari pekerjaannya secara sukarela menurut pilihannya sendiri.

Berdasarkan pendapat beberapa ahli diatas, dapat disimpulkan bahwa turnover atau keinginan berpindah merupakan kecenderungan atau niat karyawan untuk meninggalkan suatu organisasi baik yang dilakukan oleh karyawan itu sendiri maupun yang dilakukan oleh perusahaan.

\section{Hipotesis Penelitian}

Berdasarkan kajian teori dan kerangka berpikir penelitian, maka dirumuskan hipotesis sebagai berikut:

H1 : Daya tarik program insentif berpengaruh negatif signifikan terhadap keinginan pindah kerja.

$\mathrm{H} 2$ : Orientasi kapabilitas supervisor berpengaruh negatif signifikan terhadap keinginan pindah kerja.

\section{METODE}

Metode penelitian yang digunkan dalam penelitian ini adalah penelitian kuantitatif. Populasi pada penelitian ini adalah agen asuransi PT.AXA Financial Indonesia Cabang Samarinda dengan menggunakan teknik purposive sampling untuk menetukan sampel. Metode pengumpulan data yang dimaksud pada penelitian 
ini adalah menggunakan data primer dan sekunder serta alat pengukuruan atau instrumen.

Alat pengukuran atau instrumen yang digunakan ada tiga macam yaitu alat ukur daya tarik program insentif, orientasi kapabilitas supervisor dan keinginan pindah kerja (turnover intention). Teknik analisa data yang digunakan yaitu regresi linier berganda untuk mengetahui seberapa besar pengaruh variable independen terhadap variabel dependen. Sebelum dilakukan

analisis data, terlebih dahulu dilakukan uji validitas dan reliabilitas kuesioner dan analisis angka indeks. Keseluruhan teknik analisis data akan menggunakan program IBM SPSS Statistics 23.

\section{HASIL DAN PEMBAHASAN}

\section{Uji Validitas dan Reliabilitas}

Uji validitas dalam penelitian ini dilakukan dengan cara mengkorelasikan antara skor butir dengan skor total. Skor butir (pertanyaan) dipandang sebagai nilai $\mathrm{X}$ dan skor total dipandang sebagai nilai $\mathrm{Y}$, sehingga diperoleh indeks validitas setiap butir. Untuk mengetahui validitas kuesioner dilakukan dengan membandingkan rtabel dengan r-hitung. Apabila r-hitung > daripada r-tabel, maka item kuesioner tersebut dinyatakan valid. Nilai $r$ tabel dilihat pada tabel $r$ dengan $d f=n-2 \quad(n=$ jumlah responden/sampel). Pada tingkat kemaknaan 5\%, maka akan didapatkan angka $r$ tabel.

Uji reliabilitas digunakan untuk mengukur tingkat akurasi dan presisi dari jawaban yang mungkin dari beberapa pertanyaan. Dalam penelitian ini, peneliti melakukan uji reliabilitas dengan menggunakan Cronbach's Alpha dengan ketentuan apabila hasil koefisien Alpha > taraf signifikansi 60\% atau 0,6 maka kuesioner tersebut reliable. Berikut adalah hasil uji validitas dan reliabilitas:

Berdasarkan Tabel diatas, maka dapat dilihat bahwa seluruh pertanyaan untuk variabel keinginan pindah kerja, daya tarik program insentif dan orientasi kapabilitas supervisor memiliki status valid, karena nilai r-hitung (Corrected ItemTotal Correlation) > r-tabel sebesar 0,235. Tabel tersebut juga menjelaskan uji reliabilitas yang dilakukan terhadap item pertanyaan yang dinyatakan valid. Hasil koefisien reliabilitas instrument keinginan pindah kerja, daya tarik program insentif, dan orientasi kapabilatas supervior ternyata memiliki nilai Cronbach Alpha lebih besar dari 0,600 yang berarti ketiga instrumen dinyatakan reliable atau memenuhi persyaratan.

\section{Analisis Angka Indeks}

Penyampaian gambaran empiris atas data yang digunakan dalam penelitian secara deskriptif statistik adalah dengan menggunakan angka indeks. Melalui angka indeks akan diketahui sejauh mana derajat persepsi responden atas variabelvariabel yang menjadi indikator dalam penelitian. 
Rentang jawaban pengisian dimensi pertanyaan setiap variabel yang diteliti, ditentukan dengan menggunakan kriteria tiga kotak (three box method). Angka rentang indeks yang dihasilkan akan dibagi 3, sehingga menghasilkan rentang sebesar 15 yang akan digunakan sebagai dasar interpretasi nilai indeks, yaitu :

Nilai indeks $5.00-20.00=$ interpretasi Rendah

Nilai indeks $20.01-35,00=$ interpretasi Sedang

Nilai indeks $35.01-50.00=$ interpretasi Tinggi

\section{Nilai Indeks Variabel Daya Tarik Program Insentif}

Tabel 1. Nilai Indeks Variabel Daya Tarik Program Insentif

\begin{tabular}{clcccccl}
\hline \multirow{2}{*}{ No } & \multirow{2}{*}{ Indikator } & \multicolumn{9}{c}{ Indeks DPI (Nilai x Frekuensi) } & \multicolumn{2}{c}{ Angka } \\
\cline { 3 - 7 } & & $\mathbf{6}$ & $\mathbf{7}$ & $\mathbf{8}$ & $\mathbf{9}$ & $\mathbf{1 0}$ & Indeks \\
\hline 1 & DPI1 & - & 1 & 15 & 7 & 27 & $46 \%$ \\
2 & DPI2 & - & 2 & 16 & 5 & 27 & $45.7 \%$ \\
3 & DPI3 & - & - & 19 & 7 & 24 & $45.5 \%$ \\
4 & DPI4 & 2 & 3 & 18 & 7 & 20 & $44 \%$ \\
\hline Rata-Rata & & & & & & $\mathbf{4 5 . 3 \%}$ \\
\hline
\end{tabular}

Sumber: Hasil pengolahan data, 2017

Tabel tersebut menunjukkan bahwa hasil perhitungan nilai indeks variabel daya tarik program insentif (DPI) memiliki angka indeks bernilai tinggi sebesar 45.3 yang berada pada rentang 35.01 - 50.00, sehingga dapat disimpulkan bahwa variabel ini dipersepsikan tinggi oleh responden.

Tabel 2. Persepsi Responden Terhadap Variabel Daya Tarik Program Insentif

\begin{tabular}{|c|c|c|}
\hline Indikator & Nilai Indeks & Temuan Penelitian - Persepsi Responden \\
\hline $\begin{array}{l}\text { Komisi Penjualan } \\
\text { Pribadi }\end{array}$ & $46 \%$ & $\begin{array}{l}\text { Komisi } 30 \% \\
\text { Agent get Agent } 7.5 \%\end{array}$ \\
\hline $\begin{array}{l}\text { Komisi Penjualan } \\
\text { Grup }\end{array}$ & $45.7 \%$ & $\begin{array}{l}\text { Komisi 30\% } \\
\text { Komisi 35\% }\end{array}$ \\
\hline Bonus Tunai & $45.5 \%$ & $\begin{array}{l}\text { Bonus bulanan } 20 \% \\
\text { Konsistensi bonus } 15 \% \\
\text { Program Trip Luar Negeri }\end{array}$ \\
\hline Bonus Non Tunai & $44 \%$ & $\begin{array}{l}\text { Kendaraan } \\
\text { Barang }\end{array}$ \\
\hline
\end{tabular}

Sumber: Hasil pengolahan data, 2017

Tabel 2 menjelaskan temuan-temuan dalam penelitian yang merupakan pengetahuan responden terhadap program insentif PT. AXA Financial Indonesia. Berdasarkan temuan tersebut dapat disimpulkan bahwa ada 5 bentuk program insentif yang ditawarkan perusahaan kepada agennya yaitu, komisi penjualan $30 \%$ sampai $35 \%$, agent get agent sebesar $7.5 \%$, konsistensi bonus $15 \%$, bonus bulanan 
$20 \%$, serta bonus-bonus non tunai seperti program trip luar negeri, kendaraan dan barang.

Tabel 3. Nilai Indeks Variabel Orientasi Kapabilitas Supervisor

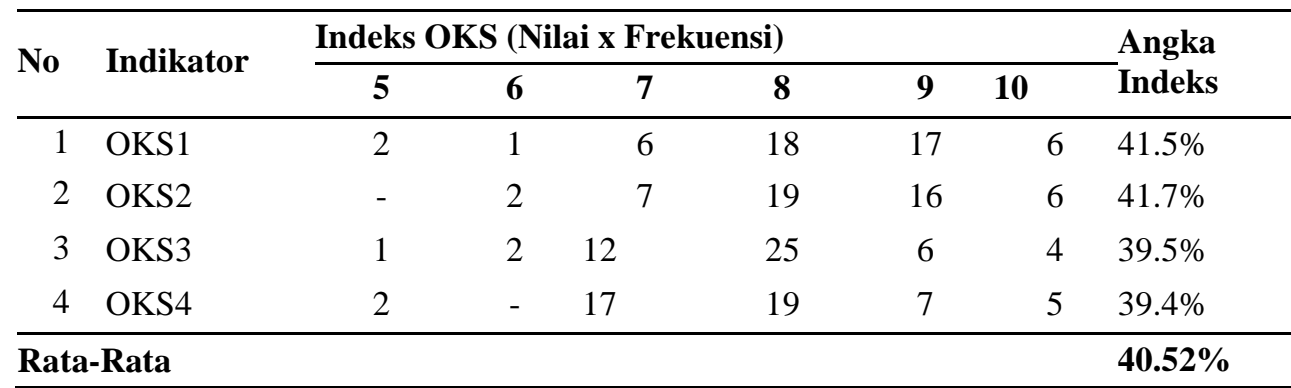

Sumber: Hasil pengolahan data, 2017

Tabel tersebut menunjukkan bahwa hasil perhitungan nilai indeks variabel orientasi kapabilitas supervisor (OKS) memiliki indeks 40.52 yang bernilai tinggi, sehingga dapat disimpulkan bahwa variabel ini dipersepsikan tinggi oleh responden.

Tabel 4. Persepsi Responden Terhadap Variabel Orientasi Kapabilitas Supervisor

\begin{tabular}{|c|c|c|}
\hline Indikator & $\begin{array}{l}\text { Nilai } \\
\text { Indeks }\end{array}$ & $\begin{array}{l}\text { Temuan Penelitian - Persepsi } \\
\text { Responden }\end{array}$ \\
\hline Menetapkan standar evaluasi & & Meeting/Pertemuan setiap minggu \\
\hline kemampuan menjual & $41.5 \%$ & Product Knowledge \\
\hline $\begin{array}{l}\text { Menyediakan penduan } \\
\text { peningkatan keterampilan } \\
\text { menjual }\end{array}$ & $41.7 \%$ & $\begin{array}{l}\text { Menyediakan panduan dalam bentuk } \\
\text { buku, CD, dan Video } \\
\text { Training }\end{array}$ \\
\hline $\begin{array}{l}\text { Mengevaluasi agen terkait } \\
\text { kemampuan }\end{array}$ & & Mengadakan meeting \\
\hline $\begin{array}{l}\text { Kemampuan } \\
\text { komunikasi dengan klien }\end{array}$ & $39.5 \%$ & Joint Visit \\
\hline Membantu agen dalam memilih & & Meeting one on one \\
\hline metode penjualan yang cocok & $39.4 \%$ & Dengan melihat prospek \\
\hline
\end{tabular}

Sumber: Hasil pengolahan data, 2017

Tabel 4 menjelaskan temuan-temuan dalam penelitian yang merupakan pengetahuan dan persepsi responden terhadap orientasi kapabilitas supervisor PT. AXA Financial Indonesia. Berdasarkan temuan tersebut dapat disimpulkan bahwa supervisor aktif melaksanakan meeting untuk mengevaluasi dan melihat sejauh mana perkembangan para agennya, supervisor juga memberikan pelatihan serta panduan-panduan untuk meningkatkan kemampuan dan keterampilan menjual agennya dalam bentuk buku, CD, dan video. Supervisor juga aktif dalam melakukan joint visit, dimana supervisor ikut mendampingi agen menemui nasabah. Hal tersebut 
membuat supervisor mengetahui dan memahami kelemahan dan kelebihan dari para agennya.

\section{Nilai Indeks Variabel Keinginan Pindah Kerja}

Tabel 5. Nilai Indeks Variabel Keinginan Pindah Kerja

\begin{tabular}{clccccccc}
\hline \multirow{2}{*}{ No } & \multirow{2}{*}{ Indikator } & \multicolumn{1}{c}{ Indeks TI (Nilai x Frekuensi) } & Angka \\
\cline { 2 - 8 } & $\mathbf{1}$ & & $\mathbf{2}$ & $\mathbf{3}$ & $\mathbf{4}$ & $\mathbf{5}$ & Indeks \\
\hline 1 & TI1 & 29 & 17 & 2 & 1 & 1 & $7.8 \%$ \\
2 & TI2 & 28 & 18 & 2 & 2 & - & $7.8 \%$ \\
3 & TI3 & 21 & 24 & 3 & 2 & - & $8.6 \%$ \\
\hline Rata-Rata & & & & & & $\mathbf{8 . 0 6 \%}$ \\
\hline
\end{tabular}

Sumber: Hasil pengolahan data, 2017

Tabel tersebut menunjukkan bahwa hasil perhitungan nilai indeks variabel keinginan pindah kerja (TI) memiliki angka indeks rendah sebesar $8.06 \%$ yang berada pada rentang nilai 5.00 - 20.00, sehingga dapat disimpulkan bahwa variabel ini dipersepsikan rendah oleh responden.

Tabel 6. Persepsi Responden Terhadap Variabel Keinginan Pindah Kerja

\begin{tabular}{lll}
\hline Indikator & \multicolumn{1}{c}{$\begin{array}{c}\text { Nilai } \\
\text { Indeks }\end{array}$} & $\begin{array}{l}\text { Temuan Penelitian - Persepsi } \\
\text { Responden }\end{array}$ \\
\hline $\begin{array}{l}\text { Sepertinya saya akan mencari pekerjaan } \\
\text { baru tahun ini }\end{array}$ & $7.8 \%$ & Tidak \\
\hline $\begin{array}{l}\text { Saya sering berfikir untuk keluar dari } \\
\text { perusahaan ini }\end{array}$ & $7.8 \%$ & Tidak \\
\hline $\begin{array}{l}\text { Kemungkinan besar saya akan mencari } \\
\text { pekerjaan baru tahun depan }\end{array}$ & $8.6 \%$ & $\begin{array}{l}\text { 1. Tidak } \\
\text { 2. Kemungkinan iya }\end{array}$ \\
\hline
\end{tabular}

Sumber: Hasil pengolahan data, 2017

Tabel 6 menjelaskan temuan-temuan dalam penelitian yang merupakan persepsi responden terhadap keinginan pindah kerja agen asuransi PT. AXA Financial Indonesia. Temuan tersebut menunjukkan bahwa para agen asuransi tidak memiliki keinginan untuk pindah kerja dalam waktu dekat, walaupun para agen sering berfikir untuk keluar dari perusahaan. Para agen beranggapan bahwa mereka mungkin akan mencari pekerjaan baru tahun depan.

Berdasarkan tabel di atas, diperoleh hasil uji regresi. Maka estimasi fungsi regresi berganda yang diperoleh adalah : $\mathrm{Y}=6.228-0,246 \mathrm{X} 1-$

$0,294 X 2$. Nilai konstanta adalah 6.228 yang mengandung arti bahwa total skor keinginan pindah kerja sebesar 6.228, jika skor X1 dan X2 =0. Nilai koefisien

X1 sebesar -0,246 artinya untuk setiap kenaikan 1 skor variabel daya tarik program insentif akan menurunkan skor keinginan pindah kerja sebesar 0,246. 
Nilai koefisien X2 sebesar -0,294 yang berarti untuk setiap kenaikan 1 skor orientasi kapabilitas supervisor akan akan menurunkan skor keinginan pindah kerja sebesar 0,294.

Output pada tabel 9 menjelaskan bahwa koefisien korelasi antara variabel independen dan dependen sebesar 0,573. Nilai 0,573 menunjukan korelasi yang terjadi antara variabel independen (daya tarik program insentif dan orientasi kapabilitas supervisor) dengan variabel dependen (keinginan pindah kerja) berada dalam kategori hubungan yang cukup $(>0,40-0,70)$.

\section{Pengaruh Daya Tarik Program Insentif terhadap Keinginan Pindah}

\section{Kerja.}

Hasil pengujian yang dilakukan terhadap variabel daya tarik program insentif serta pengaruhnya terhadap keinginan pindah kerja menunjukkan bahwa variabel daya tarik program insentif $(\mathrm{X} 1)$ memiliki nilai $\mathrm{t}=-2.274$ dan $\mathrm{Sig}=0,028<0,05$. Hal ini berarti secara parsial variabel daya tarik program insentif berpengaruh negatif signifikan terhadap keinginan pindah kerja. Hal ini menunjukkan bahwa semakin baik program insentif yang ditawarkan oleh perusahaan maka akan berdampak pada menurunnya tingkat keinginan pindah kerja. Para agen asuransi PT.AXA Financial Indonesia cabang Samarinda dalam penelitian ini merasa program insentif yang menarik dapat memotivasi para agen untuk meningkatkan produktivitas, serta merangsang para agen asuransi untuk mampu berkerja melebihi standar yang telah ditentukan oleh perusahaan. Meningkatnya produktivitas dan kinerja para agen serta pengelolaan program insentif yang baik oleh perusahaan, akan berpengaruh terhadap penurunan angka keinginan pindah kerja. Hasil penelitian ini sejalan dengan penelitian yang dilakukan oleh Gable, et al (2007) yang dalam penelitiannya menyimpulkan bahawa program insentif berdampak pada menurunnya tingkat turnover. Peterson dan Luthans (2006) juga menyimpulkan bahwa program insentif, baik finansial maupun non finansial akan menekan angka turnover.

\section{Pengaruh Orientasi Kapabilitas Supervisor terhadap Keinginan Pindah Kerja.}

Orientasi kapabilitas supervisor adalah perilaku supervisor dalam melakukan pengawasan yang lebih menekankan perhatiannya pada pengembangan keterampilan dan kemampuan individu tenaga penjual yang diawasi. Hal ini ditunjukkan untuk memastikan bahwa tenaga penjual memiliki serangkaian keterampilan dan kemampuan yang membawa kinerja yang baik (Challagalla dan Shervani, 1996:98).

Hasil penelitian ini menunjukkan bahwa variabel orientasi kapabilitas supervisor $(\mathrm{X} 2)$ memiliki nilai $\mathrm{t}=-2.753$ dan $\mathrm{Sig}=0,008<0,05$. Hal ini berarti secara parsial variabel orientasi kapabilitas supervisor berpengaruh negatif signifikan terhadap keinginan pindah kerja agen asuransi AXA Financial Indonesia cabang Samarinda. Hal ini menunjukkan bahwa semakin baik supervisor dalam melakukan pengawasan serta mengembangkan kemampuan dan keterampilan 
menjual dari para agennya maka akan berdampak pada menurunnya angka keinginan pindah kerja, karena para agen asuransi merasa termotivasi apabila supervisor mereka aktif dan terbuka dalam memberikan arahan, solusi, dan saran untuk meningkatkan kemampuan dan keterampilan menjual para agennya.

Penelitian ini didukung oleh penelitian yang dilakukan sebelumnya oleh Krackhardt, et al (1981) yang menyatakan bahwa intervensi supervisor akan berpengaruh pada turunnya tingkat turnover. Penelitian lain yang dilakukan oleh Nazenin (2014) menunjukkan bahwa turnover intention dipengaruhi oleh beberapa faktor diantaranya gaji/upah, kesempatan promosi, pengawasan, dan rekan kerja.

\section{SIMPULAN}

Berdasarkan hasil penelitian yang dilakukan untuk mengetahui bagaimana pengaruh daya tarik program insentif dan orientasi kapabilitas supervisor terhadap keinginan pindah kerja agen asuransi PT. AXA Financial Indonesia cabang Samarinda, maka dapat diambil kesimpulan sebagai berikut:

1. Variabel daya tarik program insentif memiliki pengaruh yang negatif signifikan terhadap keinginan pindah kerja agen asuransi, yang berarti jika variabel daya tarik program insentif mengalami peningkatan maka variabel keinginan pindah kerja agen asuransi akan menurun. Hal ini berarti semakin baik dan menarik program insentif yang ditawarkan oleh perusahaan, maka akan berdampak pada menurunnya keinginan pindah kerja agen asuransi.

2. Penelitian ini juga membuktikan bahwa variabel orientasi kapabilitas supervisor memiliki pengaruh yang negatif signifikan terhadap keinginan pindah kerja agen asuransi, yang artinya apabila variabel orientasi kapabilitas supervisor mengalami peningkatan maka variabel keinginan pindah kerja agen asuransi akan menurun. Hal ini menunjukkan bahwa semakin baik orientasi kapabilitas supervisor maka akan berpengaruh pada menurunnya keinginan pindah kerja agen asuransi.

\section{DAFTAR PUSTAKA}

Badillo, Rustica D. 2004. The influence of supervisors on the goal orientations of salespeople. CHED Center of Development in Business and Management Education.

Challagalla, Goutam Nand, Tassadduq Shervani. 1996., Dimensions and types of Supervisory Control : Effects on Salesperson Performance and Satisfaction, Journal of Marketing Volume.60 (January 1996), 89-105.

Ferdinand, Agusty. 2014. Metode Penelitian Manajemen : Pedoman Penelitian untuk Penulisan Skripsi Tesis dan Disertai Ilmu Manajemen. Semarang: Badan Penerbit Fakultas Ekonomika dan Bisnis Universitas Dipenogoro, Semarang.

Gable, Sara., Rothrauff, Tanja C., Thornburg, Kathy R., Mauzy, Denise. 2007. 
Cash incentives and turnover in center-based child care staff. Early Childhood Research Quarterly 22 (2007) 363-378.

Ghozali, Imam, 2013. Aplikasi Analisis Multivariat dengan Program IBM SPSS 21. Edisi 7, Penerbit Universitas Diponegoro, Semarang.

Harnoto. 2002. Manajemen Sumber Daya Manusia. Prehallindo, Jakarta. Hartono, Jogiyanto. 2013. Metodologi Penelitian Bisnis Salah Kaprah dan

Pengalaman-pengalaman. Edisi 5. BPFE-Yogyakarta. Yogyakarta. Hasibuan, S.P., Malayu. 2005. Organisasi dan Motivasi : Dasar Peningkatan Produktivitas. Bumi Aksara, Jakarta.

Hasibuan, S.P., Malayu. 2009. Manajemen : Dasar, Pengertian dan Masalah Edisi Revisi, PT. Bumi Aksara, Jakarta.

Jones, Eli., Chonko, L., Rangajaran, D., Roberts, J. 2007. The Role of Overload on Job Attitudes, Turnover Intentions, and Salesperson Performance., Journal of Business Research 60 (2007) 663-671.

Kohli, A. K., Shervani, T. A., Challagalla. 1998. Learning and Performance Orientation of Salespeople The Role of Supervisors., Journal of Marketing Reserach Volume.XX:XV. (May 1998), 263-274.

Krackhardt, David., McKenna, John., Porter, Lyman W., Steers, Richard M. 1981. Supervisory Behavior and Employee Turnover; A Field Experiment. Academy of Management Journal.

Lee, Chun-Chang., Huang, Sheng-Hsiung., Yi Zhao, Chen. 2010. A Study On Factors Affecting Turnover Intention Of Hotel Empolyees., Asian Economic and Financial Review.

Mangkunegara, Anwar Prabu. 2009. Manajemen Sumber Daya Manusia, PT. Remaja Rosdakarya, Bandung.

Mathis, Robert L dan Jackson, John H, 2004. Manajemen Sumber Daya Manusia, Buku ke dua. Salemba Empat, Jakarta.

Mintzberg, H. 1973. The Nature of Managerial Work. Harper \& Row, New York.

Mondy, R. Wayne. 2008. Manajemen Sumber Daya Manusia. Erlangga, Jakarta.

Mursid, Ali. 2008. Orientasi Pengawasan Supervisor terhadap Orientasi

Kinerja Tenaga Penjual. Fokus Ekonomi, Vol.3 No.1, Juni 2008:107-115.

Nazenin, Syarifah. 2014. Peran Stres Kerja Dan Kepuasan Kerja Untuk Mengurangi Turnover Intention. Jurnal Dinamika Manajemen, Vol. 5, No. 2, 2014, pp: 220-227. 
Panggabean, S., Mutiara. 2004. Manajemen Sumber Daya Manusia. Ghalia Indonesia, Bogor.

Pathak, Suman., Tripathi, Vibhuti. 2010. Sales Force Turnover: An Exploratory Study of the Indian Insurance Sector. Management Volume 5.

Peterson, Suzanne J..Luthans, Fred. 2006. The Impact of Financial and Nonfinancial Incentives on Business-Unit Outcomes Over Time. Journal of Applied Psychology, Vol. 91, No. 1, 156-165.

Ranupandojo, H., dan Suad Husnan. 2002. Manajemen Personalia, BPFE, Yogyakarta.

Rich, Gregory. 1997. The Sales Manager as a Role Model: Effects on Trust, Job Satisfaction, and Performance Salespeople. Journal of the Academy of Marketing Science, Volume 25, No. 4, pages 319-238.

Robbins SP, dan Judge. 2007. Perilaku Organisasi., Salemba Empat, Jakarta. Sarwono, Jonathan. 2006. Metode Penelitian Kuantitatif \& Kualitatif. Graha Ilmu, Yogyakarta.

Sarwoto. 2010. Dasar-Dasar Organisasi dan Manajemen, cetakan keenambelas. Ghalia, Jakarta.

Schein, Edgar.H. 1996. Culture: The Missing Concept in Organization Studies. Administrative Science Quarterly, page 229.

Shapira, Zur., Dunbar, Roger.L.M. 1980. Testing Mintzberg's Managerial Roles Classification Using an in-Basket Simulation. Journal of Applied Psychology, Vol. 65, No. 1, page 87-95.

Siagian, Sondang P. 2009. Kiat Meningkatkan Produktivitas Kerja. PT Rineka Cipta, Jakarta. 